\title{
SPATIALLY VARYING GROUND MOTION MODELS AND THEIR APPLICATION TO THE ESTIMATION OF DIFFERENTIAL GROUND MOTION
}

\author{
Keiichi TAMURA*, Steven R.WINTERSTEIN** \\ and Haresh C.SHAH***
}

\begin{abstract}
Two simple stochastic models of spatially varying ground motion are established and calibrated from strong motion array data at four sites in Shizuoka Prefecture, Japan. These adopt a stationary random field model of each event's ground displacement in time and space. These models are applied to estimate maximum relative displacement between two points on the ground surface. Good agreement is found with observed relative displacement, both root mean square values and maximum values.
\end{abstract}

Keywords : ground motion, spatial variation, stochastic process, array observation

\section{INTRODUCTION}

In the seismic design of buried lifeline facilities such as pipeline systems and underground tunnels, the spatial variation of ground motion along structures should be carefully considered. From an engineering point of view, the seismic deformation method $^{1)}$, which considers spatial patterns of seismic ground deformation, was developed and is now in practical use in Japan. While structural performance during earthquakes is governed by the precise ground motion details, in the seismic deformation method these motions are estimated from a simple model of amplification and propagation characteristics of seismic waves in surface strata. This is mostly due to the lack of simultaneous ground motion data at multiple spatial locations. The spatial variation of ground motion may also have significant influence on the seismic response of multiple-span bridges and widely spread tanks.

The recent development of closely spaced arrays of accelerographs ${ }^{2)-4)}$ has provided valuable data for the analysis of ground motion and its spatial variation. Numerous studies have been reported with the data recorded at the SMART-1 array located in Lotung, Taiwan. These studies mainly focus on differential ground motion, seismic wave propagation and simulation of ground motion.

Two simple variants of standard ground motion

* Member of JSCE, Senior Research Engineer, Ground Vibration Division, Public Works Research Institute, Ministry of Construction (1 Asahi, Tsukuba-shi, Ibaraki-ken 305 Japan)

** Ph. D., Engineering Research Associate, Department of Civil Engineering, Stanford University

*** Ph. D., Professor and Chairman, Department of Civil Engineering, Stanford University spectral models are established and calibrated here from strong motion array data at four sites in Shizuoka Prefecture, Japan. These adopt a stationary Gaussian random field model of each event's ground displacement in time and space ${ }^{5)}$. Although adequacy for assuming temporal and spatial stationarity of ground motion owes a lot to further studies, this assumption may be acceptable at present $t^{(6)}$. The first and simplest model assumes that the time-space covariance function of ground motion is a separable function of time and space. The second model chooses a coherence function that varies with separation length but is independent of frequency. Coherence variation with frequency has been studied ${ }^{7>9)}$, however this variation may not be very systematic and can be somewhat sensitive to data smoothing. This motivates to employ a frequency independent coherence model in this study for simplicity.

These models are applied to estimate maximum relative displacement between two points on the ground surface, using conventional Poisson models of temporal and spatial extremes ${ }^{5}$. Good agreement is found with observed relative displacement, both root mean square values and maximum values.

\section{STOCHASTIC FORMULATION OF GROUND MOTION}

\section{(1) Background}

Assuming that the earthquake ground motion displacement $u(t, x)$ results from a stationary Gaussian process with zero mean which is a function of both time $t$ and spatial coordinates $x$, the time-space covariance function $C(\tau, \eta)$ is defined as

$$
C(\tau, \eta)=E[u(t+\tau, x+\eta) u(t, x)] \cdots \cdots(1)
$$




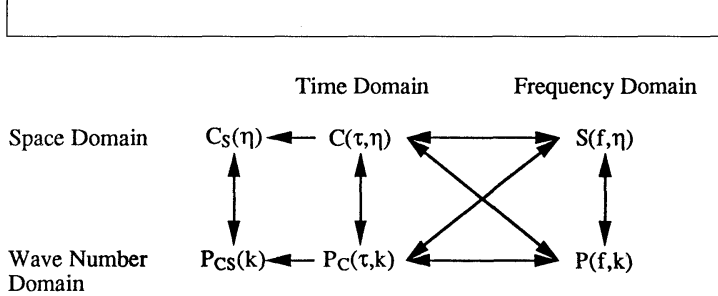

Fig.1 Relationship among stochastic functions for timespace varying process

where $E[$ ] represents the expectation operator. Transforming time lag $\tau$ into frequency $f$ by means of the Wiener-Khinchine relationship, the timespace cross spectral density function $S(f, \eta)$ can be obtained as

$$
S(f, \eta)=\int_{-\infty}^{\infty} C(\tau, \eta) \exp (-i 2 \pi f \tau) d \tau
$$

Viewing the displacement process over space at a fixed time, substituting $\tau=0$ into Eq.(1) yields the spatial covariance function $C_{s}(\eta)$ as

$$
C_{s}(\eta)=C(0, \eta)=\sigma_{u}^{2} \rho_{s}(\eta)
$$

where $\sigma_{u}^{2}$ and $\rho_{s}(\eta)$ are the mean square value of displacement and spatial correlation function, respectively. If the time-space process is assumed to be ergodic and its mean value has been removed, $\sigma_{u}^{2}$ can be estimated as

$$
\sigma_{u}^{2}=\lim _{T \rightarrow \infty} \frac{1}{T} \int_{0}^{T} u(t, x)^{2} d t
$$

where $T$ is duration of ground motion. Fig. 1 shows the relationship among Eqs.(1), (2) and (3). The functions listed in the lower row of Fig.1 are translations into the wave number domain. Those functions are related to each other by the WienerKhinchine relationship.

Typical previous studies on the time-space variation of ground motion can be classified into three groups. One approach is to model the timespace cross spectral density function $S(f, \eta)$. Assuming that seismic wave propagates horizontally, Eq.(2) may be described as

$$
S(f, \eta)=S_{0}(f) \gamma(f, \eta) \exp (-i 2 \pi f \eta / c) \cdot \cdot(5)
$$

where $S_{0}(f)$ is the power spectral density function of displacement $u$ at any fixed location $x, \gamma(f, \eta)$ is the coherence function, and $c$ is the apparent propagation velocity of seismic wave. Several models of coherence function have been proposed $^{(6) 9)}$. A second approach is to model the spatial correlation function $\rho_{s}(\eta)^{8,10), 11}$. Finally, a third approach focuses on the frequency-wave number spectrum, which may be used to simulate ground motions ${ }^{12), 13)}$.

A number of studies ${ }^{7), 8), 10,11)}$ discuss differential ground motion characteristics based on stochastic ground motion models. Comparing with these studies, the presenting study is characterized by establishing simple and practical time-space varying ground motion models and applying these models to estimate both temporal and spatial maximum relative displacement between two points on the ground surface.

(2) Proposed Time-Space Separable Correlation Model

We consider here two simple models and their practical differences. The simplest model assumes that the time-space covariance function is a separable function of time and space. Eq.(1) can then be written as

$$
C(\tau, \eta)=C_{0}(\tau) \rho_{s}(\eta)=\sigma_{u}^{2} \rho_{T}(\tau) \rho_{s}(\eta) \cdots(6)
$$

where $\rho_{T}(\tau)$ is the displacement correlation function in time at any fixed spatial location $x$, and $\rho_{s}(\eta)$ is the correlation function in space at any fixed time $t$. Let us call this model as the "timespace separable correlation model". $C_{0}(\tau)$ links to $S_{0}(f)$ in Eq. (5) by means of the Wiener-Khinchine relationship as

$$
C_{0}(\tau)=\int_{-\infty}^{\infty} S_{0}(f) \exp (i 2 \pi f \tau) d f \cdots \cdots \cdots \cdots
$$

Therefore, this model is completely defined by $\rho_{s}(\eta)$, and either $C_{0}(\tau)$ or $S_{0}(f)$.

The advantage of Eq.(6) lies in its simplicity. It may be viewed as a special case of Eq.(5) in which the following conditions have been assumed:

1) The coherence $r(f, \eta)$ is alternatively viewed as the spatial correlation function:

$$
r(f, \eta)=\rho_{s}(\eta)
$$

2) The apparent seismic wave propagation velocity $c$ is taken to be infinite.

We relax these conditions, at the expense of increased data analysis, with the alternative model described below.

\section{(3) Proposed Frequency Independent Coher-} ence Model

In this model we assume only that the coherence function $r(f, \eta)$ is independent of frequency, so that Eq.(5) can be reduced to

$$
S(f, \eta)=S_{0}(f) \gamma(\eta) \exp (-i 2 \pi f \eta / c) \cdots(9)
$$

We call this the "frequency independent coherence model". While the time-space separable correlation model required only $S_{0}(f)$ and $\rho_{s}(\eta)$, this model requires $S_{0}(f), \gamma(\eta)$ and $c$. Once these quantities have been estimated, the resulting spatial correlation function $\rho_{s}(\eta)$ inferred from this model can be found as follows.

From Eq.(9), $C(\tau, \eta)$ is expressed as

$$
\begin{aligned}
& C(\tau, \eta)=\int_{-\infty}^{\infty} S(f, \eta) \exp (i 2 \pi f \tau) d f \\
& =\gamma(\eta) \int_{-\infty}^{\infty} S_{0}(f) \exp \{i 2 \pi f \\
& (\tau-\eta / c)\} d f
\end{aligned}
$$


Combining Eqs.(7) and (10), $C(\tau, \eta)$ is written as $C(\tau, \eta)=\gamma(\eta) C_{0}(\tau-\eta / c)$

$$
=\sigma_{u}^{2} \gamma(\eta) \rho_{T}(\tau-\eta / c)
$$

Substituting $\tau=0$ into Eq.(11) yields the desired spatial correlation result for this model:

$$
\rho_{s}(\eta)=\gamma(\eta) \rho_{T}(-\eta / c)
$$

This result reduces to Eq.(8), if $c$ becomes infinite. In the numerical example that follows, we compare this inferred $\rho_{s}(\eta)$ with that estimated directly from the data.

\section{RELATIVE DISPLACEMENT STATISTICS}

\section{(1) Correlation Statistics}

The relative displacement $d(t, x ; \xi)$ between two points with the separation distance $\xi$ is given by

$$
d(t, x ; \xi)=u(t, x+\xi)-u(t, x)
$$

Since $u(t, x)$ is assumed to be a stationary Gaussian time-space process, $d(t, x ; \xi)$ is also Gaussian process with zero mean. For a fixed relative distance $\xi, d(t, x ; \xi)$ will vary with both time $t$ and spatial location $x$. The time-space covariance function of relative displacement $C_{d}(\tau$, $\eta ; \xi)$ is expressed in terms of the corresponding displacement covariance function as

$$
\begin{aligned}
C_{d}(\tau, \eta ; \xi)= & E[d(t+\tau, x+\eta ; \xi) d(t, x ; \xi)] \\
= & E[\{u(t+\tau, x+\eta+\xi) \\
& -u(t+\tau, x+\eta)\}\{u(t, x+\xi) \\
& -u(t, x)\}] \\
= & 2 C(\tau, \eta) \\
& -C(\tau, \eta+\xi)-C(\tau, \eta-\xi)
\end{aligned}
$$

Eq.(14) is completely general in this form. To specialize it to the time-space separable correlation model or frequency independent coherence model, $C(\tau, \eta)$ should be replaced by Eq.(6)or Eq.(11). The mean square value of relative displacement can be obtained by setting $\tau=\eta=0$ in Eq.(14) :

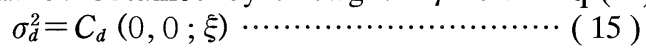

(2) Maximum Relative Displacement Statistics

Practical quantities of engineering interest include the absolute maximum value, $d_{\max }=\max \mid d$ $(t, x ; \xi) \mid$, of the relative displacement over either time or space. Statistics of these quantities can be estimated from random process theory ${ }^{5,14), 15}$. In particular, for the maximum over a time or space window of length $B$, the $p$-fractile of $d_{\max }$ can be estimated as

$$
\frac{d_{\max }}{\sigma_{d}}=\left\{\begin{array}{l}
\sqrt{2 \ln \left\{-\frac{2 B}{L_{D} \ln p}\right\}} \cdots-\frac{2 B}{L_{D} \ln p} \geq e \\
\sqrt{2} \cdots \cdots \cdots \cdots \cdots \cdots \cdots \text { otherwise }
\end{array}\right.
$$

Table 1 Earthquakes analyzed

\begin{tabular}{llllll} 
Site & Date & $\begin{array}{l}\text { Epicentral } \\
\text { Region }\end{array}$ & Magnitude & $\begin{array}{l}\text { Epicentral } \\
\text { Distance[km] }\end{array}$ & $\begin{array}{l}\text { Azimuth } \\
\text { [degree] }\end{array}$ \\
\hline Sagara & 1983.11 .24 & $\begin{array}{l}\text { SCoast } \\
\text { of Chubu }\end{array}$ & 5.0 & 45 & 277 \\
Yaizu & 1984. 9.14 & $\begin{array}{l}\text { Central } \\
\text { Chubu }\end{array}$ & 6.8 & 126 & 327 \\
Numazu & 1988.9 .5 & $\begin{array}{l}\text { E Yamanashi } \\
\text { Prefecture }\end{array}$ & 5.6 & 45 & 25 \\
Matsuzaki & 1986.11 .22 & $\begin{array}{l}\text { Near Izu- } \\
\text { Oshima Is. }\end{array}$ & 6.0 & 72 & 108 \\
\hline
\end{tabular}

in which $\sigma_{d}$ is given by Eq.(15), and $L_{D}$ is estimated as

$$
\begin{aligned}
& L_{D T}=\left.2 \pi \sqrt{\frac{C_{d}(\tau, \eta ; \xi)}{-\partial^{2} C_{d}(\tau, \eta ; \xi) / \partial \tau^{2}}}\right|_{\tau=\eta=0} \\
& \quad \text { for temporal maximum } \cdots \cdots \cdots \cdots \\
& L_{D S}=\left.2 \pi \sqrt{\frac{C_{d}(\tau, \eta ; \xi)}{-\partial^{2} C_{d}(\tau, \eta ; \xi) / \partial \eta^{2}}}\right|_{\tau=\eta=0} \\
& \quad \text { for spatial maximum } \cdots \cdots \cdots \cdots \cdots
\end{aligned}
$$

\section{ANALYSIS OF ARRAY DATA}

\section{(1) Array Data Analyzed}

The array data obtained at 4 sites in Shizuoka Prefecture, Japan are used in this analysis. The array observation is conducted by the Public Works Research Institute, Ministry of Construction, $\mathrm{Japan}^{4)} .14$ to 18 tri-axial 16 bits digital strong motion accelerographs including down-hole accelerometers are installed at each site. Fig. 2 shows the array deployment. The array records analyzed here were obtained from 4 earthquakes shown in Table 1.

Displacement of ground motion is calculated by integrating acceleration record twice in the frequency domain ${ }^{16)}$. Referring to the practical recording accuracy of the digital accelerograph ${ }^{17)}$, the lower and upper cut-off frequencies are selected as $1 / 5 \mathrm{~Hz}$ and $20 \mathrm{~Hz}$, respectively.

Since the original acceleration time histories are recorded along north-south and east-west directions, the radial and transverse components of displacement are calculated by rotating the coordinates. Fig.3 shows an example of displacement time histories.

(2) Temporal and Spatial Correlation Functions

The following function is assumed to represent temporal correlation function (auto-correlation function) of ground displacement :

$$
\rho_{T}(\tau)=\frac{\cos \left(2 \pi \tau / T_{0}\right)}{\left(2 \pi \alpha \tau / T_{0}\right)^{2}+1}
$$

where $T_{0}$ and $\alpha$ are determined by least squares fit to the auto-correlation function calculated from displacement data. An example of the least squares fits is shown in Fig.4. The solid and dashed lines 


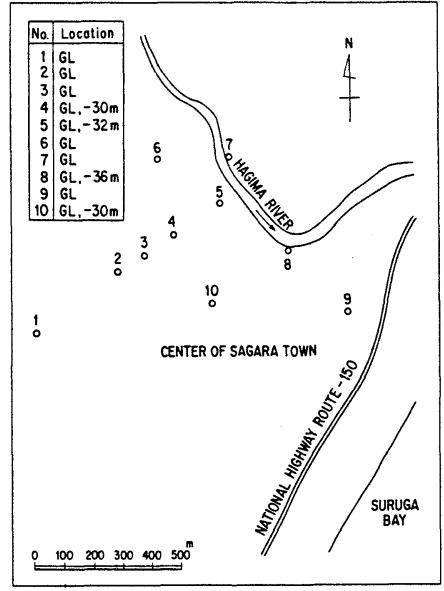

(a) Sagara site

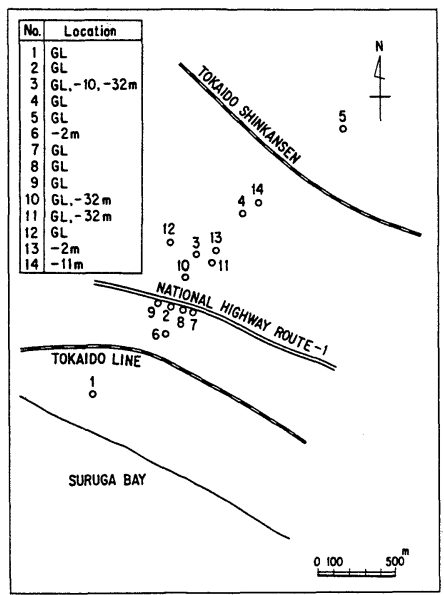

(c) Numazu site

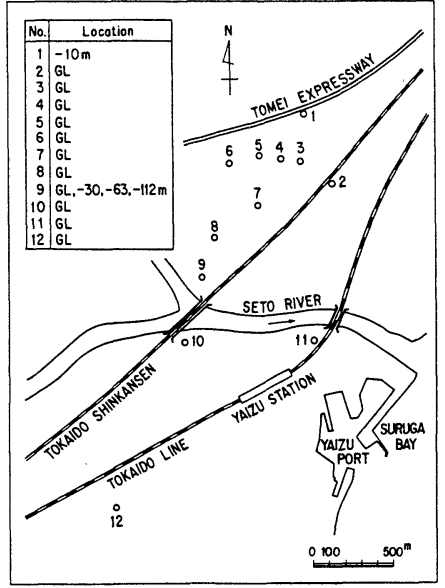

(b) Yaizu site

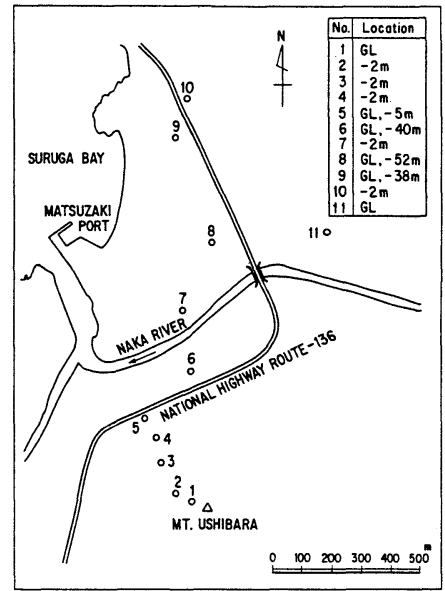

(d) Matsuzaki site

Fig.2 Array deployment

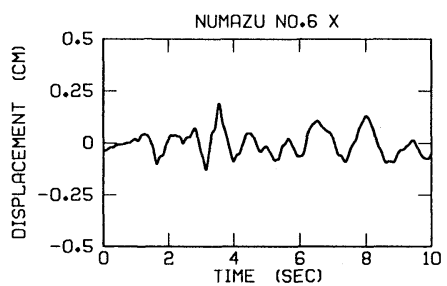

(a) No.6

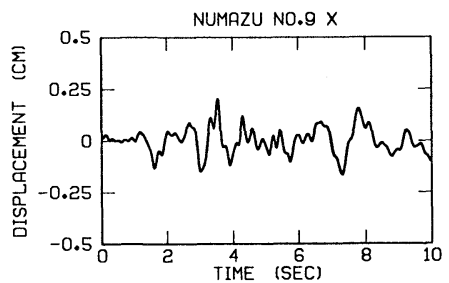

(b) No.9

Fig.3 Example of displacement time histories (Numazu, radial component)

correspond to auto-correlation functions calculated from the observed data and Eq.(19), respectively.

For the spatial correlation function in the timespace separable correlation model, the following function is adopted :

$$
\rho_{s}(\eta)=\left\{1-\left(\eta / \xi_{0}\right)^{2}\right\} \exp \left\{-\left\{\eta / \xi_{0}\right)^{2}\right\}
$$

where $\xi_{0}$ is determined by least squares fit to the spatial correlation coefficients calculated from displacement records. Fig.5 compares the least squares fit function indicated by solid line and correlation coefficients calculated from the observed data. The dashed line in Fig.5 shows the spatial correlation function inferred from the 


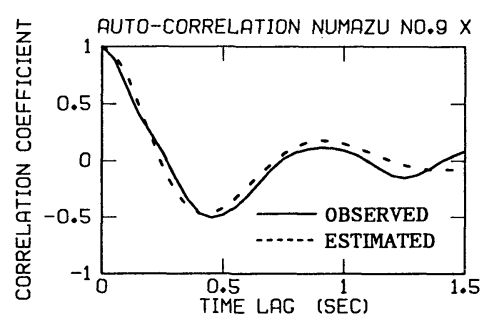

Fig.4 Temporal correlatiom function (Numazu, No.9, radial component)

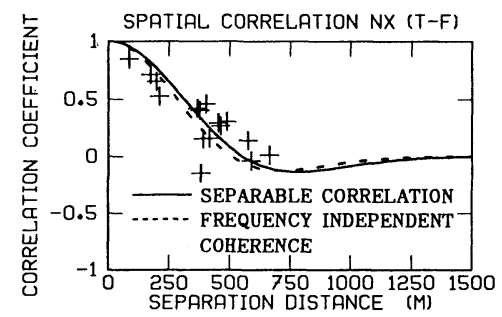

Fig.5 Spatial correlation function (Numazu, radial component)

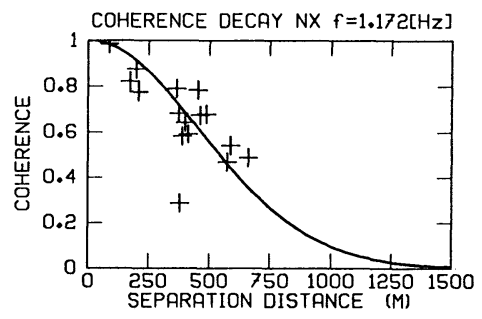

Fig.6 Coherence decay (Numazu, radial component)

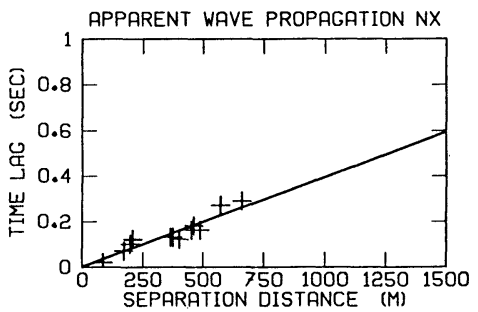

Fig.7 Apparent propagation of seismic wave (Numazu, radial component)

Table 2 Parameters of ground motion model

(a) Radial component

\begin{tabular}{lllllllllll} 
Site & $\begin{array}{l}\mathrm{B}_{\mathrm{T}} \\
{[\mathrm{sec}]}\end{array}$ & $\begin{array}{l}\text { \# of Sta } \\
\text {-tions }\end{array}$ & $\begin{array}{l}\mathrm{u}_{\max } \\
{[\mathrm{cm}]}\end{array}$ & $\begin{array}{l}\sigma_{\mathrm{u}} \\
{[\mathrm{cm}]}\end{array}$ & $\begin{array}{l}\mathrm{T}_{0} \\
{[\mathrm{sec}]}\end{array}$ & $\alpha$ & $\begin{array}{l}\xi_{0} \\
{[\mathrm{~m}]}\end{array}$ & $\begin{array}{l}\mathrm{B}_{\mathrm{s}} \\
{[\mathrm{m}]}\end{array}$ & $\begin{array}{l}\mathrm{a}_{0} \\
{[\mathrm{~m}]}\end{array}$ & $\begin{array}{l}\mathrm{c} \\
{[\mathrm{m} / \mathrm{s}]}\end{array}$ \\
\hline $\begin{array}{l}\text { Saga- } \\
\text { ra }\end{array}$ & $\begin{array}{l}3.0- \\
8.5\end{array}$ & 8 & 0.239 & .0792 & 0.70 & 0.25 & 470 & 1000 & 760 & 2635 \\
Yaizu & $\begin{array}{l}1.0- \\
9.0\end{array}$ & 8 & 0.937 & .4145 & 1.65 & 0.15 & 530 & 2000 & 960 & 1276 \\
& & & & & & & & & \\
Numa & $\begin{array}{l}2.5- \\
\text {-zu }\end{array}$ & 7.5 & 0.171 & .0675 & 0.80 & 0.30 & 550 & 1500 & 650 & 2526 \\
$\begin{array}{l}\text { Matsu } \\
\text {-zaki }\end{array}$ & $\begin{array}{l}7.0- \\
13.0\end{array}$ & 7 & 0.193 & .0816 & 1.00 & 0.15 & 380 & 1000 & 370 & 1573
\end{tabular}

(b) Transverse component

\begin{tabular}{lllllllllll} 
Site & $\begin{array}{l}\mathrm{B}_{\mathrm{T}} \\
{[\mathrm{sec}]}\end{array}$ & $\begin{array}{l}\text { \# of Sta } \\
\text {-tions }\end{array}$ & $\begin{array}{l}\mathrm{u}_{\max } \\
{[\mathrm{cm}]}\end{array}$ & $\begin{array}{l}\sigma_{\mathrm{u}} \\
{[\mathrm{cm}]}\end{array}$ & $\begin{array}{l}\mathrm{T}_{0} \\
{[\mathrm{sec}]}\end{array}$ & $\alpha$ & $\begin{array}{l}\xi_{0} \\
{[\mathrm{~m}]}\end{array}$ & $\begin{array}{l}\mathrm{B}_{\mathrm{S}} \\
{[\mathrm{m}]}\end{array}$ & $\begin{array}{l}\mathrm{a}_{0} \\
{[\mathrm{~m}]}\end{array}$ & $\begin{array}{l}\mathrm{c} \\
{[\mathrm{m} / \mathrm{s}]}\end{array}$ \\
\hline $\begin{array}{l}\text { Saga- } \\
\text { ra }\end{array}$ & $\begin{array}{l}3.0- \\
8.5\end{array}$ & 8 & 0.298 & .0951 & 0.70 & 0.15 & 480 & 1000 & 810 & 2798 \\
Yaizu & $\begin{array}{l}7.0- \\
15.0\end{array}$ & 8 & 1.141 & .5278 & 2.00 & 0.30 & 910 & 2000 & 1370 & 1632 \\
& & & & & & & & & \\
$\begin{array}{l}\text { Numa } \\
\text {-zu }\end{array}$ & $\begin{array}{l}2.5- \\
8.5\end{array}$ & 7 & 0.260 & .0793 & 0.85 & 0.20 & 580 & 1500 & 860 & 2740 \\
$\begin{array}{l}\text { Matsu } \\
\text {-zaki }\end{array}$ & $7.0-$ & 7 & 0.202 & .1001 & 1.10 & 0.15 & 550 & 1000 & 380 & 1920
\end{tabular}

frequency independent coherence model, which will be mentioned in Section 4. (3). The separation distance in Fig.5 is the distance between two points projected to radial direction.

Table 2 shows the parameters of temporal and spatial correlation functions. $B_{T}$ and $B_{S}$ represent temporal and spatial interval in which stationarity of ground motion is assumed, respectively. Besides these parameters, the maximum ground displace- ment $u_{\text {max }}$ and root mean square value of displacement $\sigma_{u}$ for each site are also shown in the same table. $u_{\max }$ and $\sigma_{u}$ are the mean values among stations in each site.

\section{(3) Spatial Coherence and Propagation Veloc- ity of Seismic Wave}

The following frequency independent function is adopted to represent coherence decay with separation distance $\eta$ : 


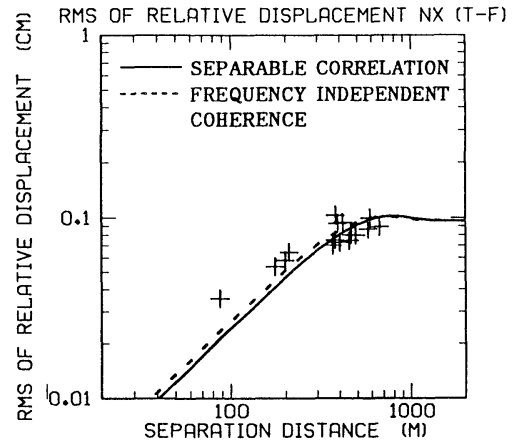

Fig.8 RMS of relative displacement (Numazu, radial component)

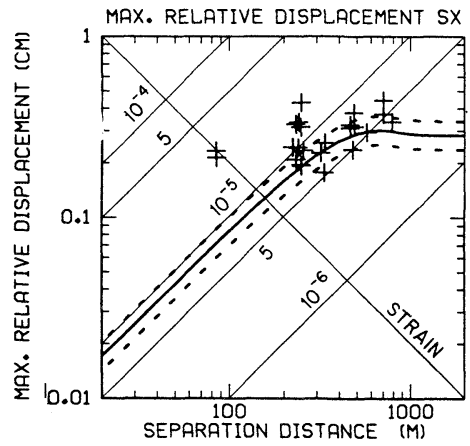

(a) Sagara, radial component

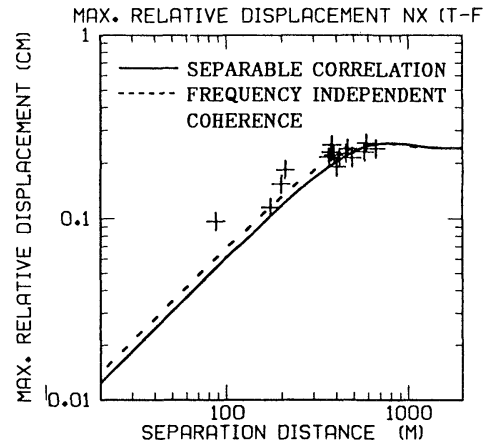

Fig.9 Temporal maximum relative displacement (Numazu, radial component, $p=0.5$ )

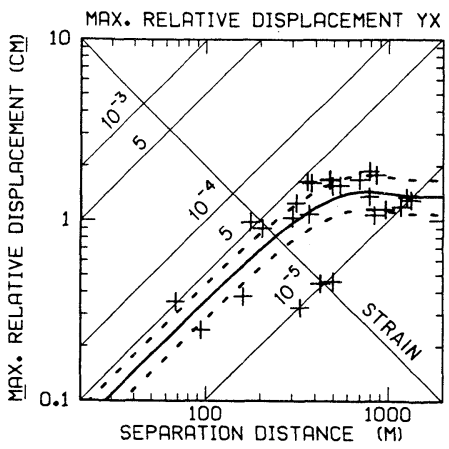

(b) Yaizu, radial component

Fig.10(1) Temporal maximum relative displacement estimated from time-space separable correlation model $(p=0.84,0.5,0.16)$

$\gamma(\eta)=\exp \left\{-\left(\eta / a_{0}\right)^{2}\right\}$

where $a_{0}$ is determined by least squares fit. Fig. 6 shows the comparison of least squares fit function and coherence calculated from the observed data, in which coherence is calculated for the predominant frequency of ground motion. A 3-point Hamming spectral window, with $\Delta f=0.098[\mathrm{~Hz}]$, is passed over the data 10 times for smoothing. The parameter $a_{0}$ is shown in Table 2 for each site.

The propagation velocity of seismic wave is calculated by utilizing cross-correlation analysis. Fig. 7 shows the relationship between separation distance of stations and time lag at which the crosscorrelation function takes its maximum value. The apparent propagation velocity, $c$ in Eq.(9), is estimated by least squares fit to these points. Values of the seismic wave propagation velocity for each site are shown in Table 2.

Substituting Eqs.(19), (21) and the propagation velocity of seismic wave $c$ into Eq.(12), the inferred spatial correlation function can be estimated from the frequency independent coherence model. This inferred spatial correlation function is shown by the dashed line in Fig.5. The directly fitted spatial correlation function of Eq.(20) is also shown in the same figure. Comparing these results, the spatial correlation functions estimated from both models are seen to agree fairly well.

\section{(4) Maximum Relative Displacement}

Fig. 8 compares the root mean square values of relative displacement $\sigma_{d}$ estimated from the timespace separable correlation model and the frequency independent coherence model, with values calculated from the observed data. The solid and dashed lines correspond to the former and the latter models, respectively. It can be seen from Fig.8 that results from both models agree quite well and show good agreement with the observed data.

Fig.9 shows the temporal maximum relative displacement between any fixed spatial locations evaluated from the time-space separable correlation model (solid line) and the frequency independent cohlerence model (dashed line), where the probability of not being exceeded $p$ is taken as 0.5 . The calculated values from the observed data are 


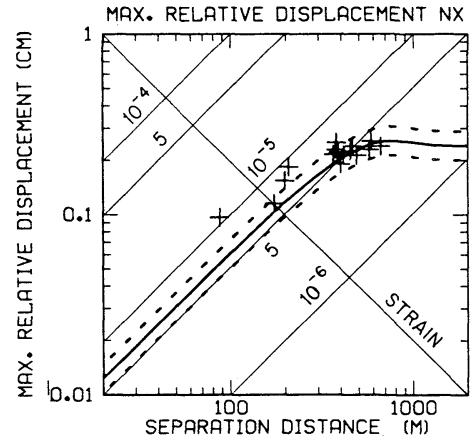

(c) Numazu, radial component

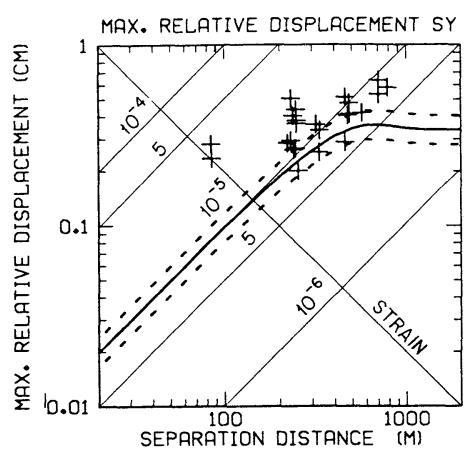

(e) Sagara, transverse component

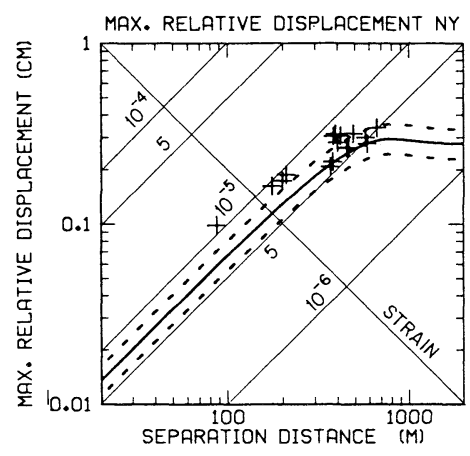

(g) Numazu, transverse component

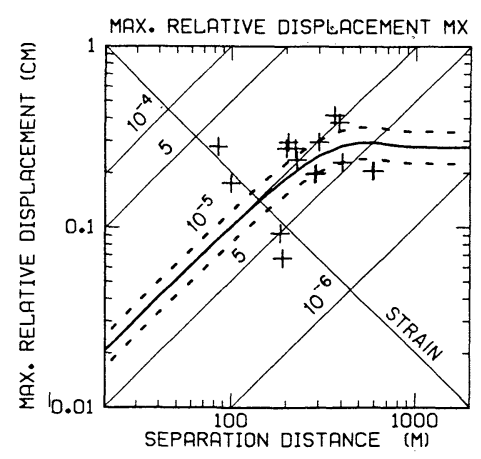

(d) Matsuzaki, radial component

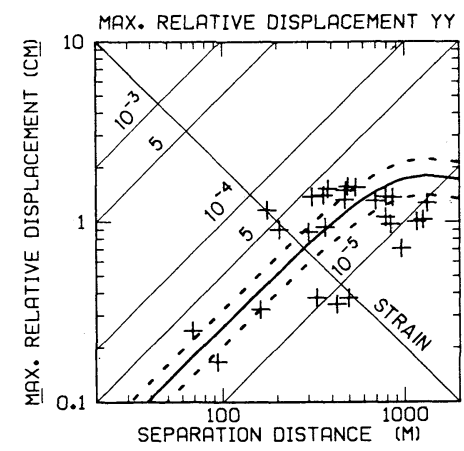

(f) Yaizu, transverse component

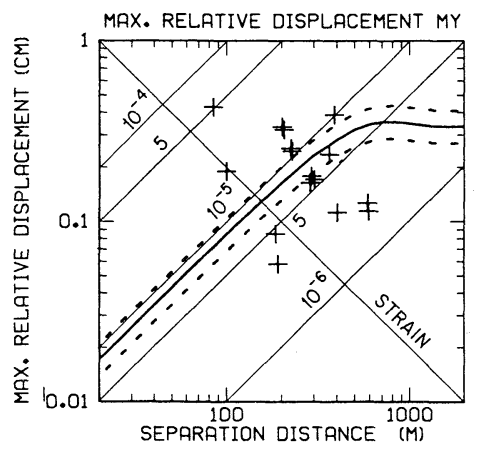

(h) Matsuzaki, transverse component

Fig.10(2) Temporal maximum relative displacement estimated from time-space separable correlation model $(p=0.84,0.5,0.16)$

also shown in the same figure. As seen from this figure, both model results agree well.

Fig.10 shows the temporal maximum relative displacement estimated from the time-space separable correlation model and calculated from the observed data, for all sites. The solid line and dashed lines correspond to $p=0.5$ and $p=0.84$, 0.16 , respectively. The range between two dashed lines indicates roughly one standard deviation dispersion from the mean value consistent with a Gaussian distribution. Though certain scatter can be seen, the theoretical formula of maximum relative displacement agrees well with the trend of observed data. Note that the range between 0.16 and 0.84 fractiles appear too narrow. This is because they include only random process uncertainty in the Gaussian model, not gross uncertainty in the model and its parameters. Temporal and spatial nonhomogeneity of the records may also contribute to this scatter.

The maximum ground strain between two points can be described as 


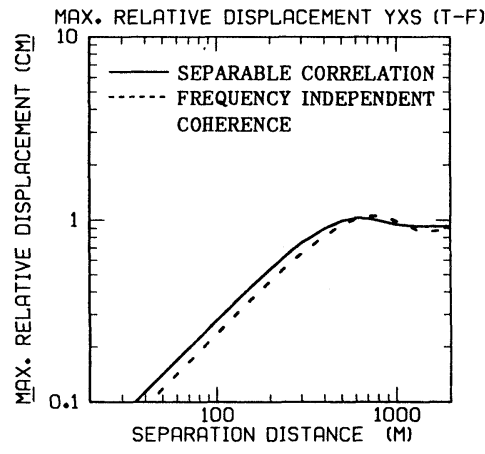

(a) Yaizu, radial component

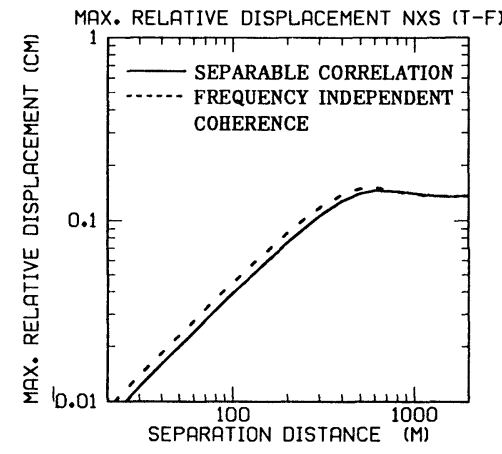

(b) Numazu, radial component

Fig.11 Spatial maximum relative displacement $(p=0.5)$

$\varepsilon_{\max }=d_{\max } / \xi$

where $\xi$ is a separation distance between two points. From the definition by Eq.(22), the maximum ground strain can be read from axes which go up from left to right with 45 degrees in Fig.10. The maximum temporal ground strains over an any fixed distance are $(25-35) \times 10^{-6}$ for Yaizu site and $(6-10) \times 10^{-6}$ for other sites, when $p$ is taken as 0.5 .

Fig.11 shows the spatial maximum relative displacement at any fixed time estimated from the time-space separable correlation model and the frequency independent coherence model, where the solid and dashed lines correspond to the former and the latter models, and $p$ is taken as 0.5 . Results are shown for Yaizu and Numazu sites. The maximum spatial ground strains at any fixed time are about $30 \times 10^{-6}$ for Yaizu site and $(4-7) \times 10^{-6}$ for other sites, when the probability of not being exceeded is taken as 0.5 .

\section{CONCLUSIONS}

Two stochastic ground motion models are proposed and applied to estimate the maximum relative displacement over a temporal or spatial interval between two points. Numerical results are calibrated with the array observation data. The following points may be concluded from the presenting study.

1) The proposed ground motion models, the time-space separable correlation model and the frequency independent coherence model can give useful engineering models of both the root mean square and maximum relative displacement.

2) Little difference exists between the timespace separable correlation model and the frequency independent coherence model, once the spatial correlation function in the former model and the spatial coherence in the latter model are suitably estimated.
3) Both models have been found to yield relatively accurate relative displacement statistics over separation distance up to $1-2 \mathrm{~km}$. Their results generally lie within the scatter shown between observations at various sites.

\section{ACKNOWLEDGMENTS}

The authors would like to express their sincere thanks to Prof. Takanori Harada, Miyazaki University, Japan for his helpful discussions. Support provided by the John A. Blume Earthquake Engineering Center, Department of Civil Engineering, Stanford University is also gratefully acknowledged.

\section{REFERENCES}

1) Public Works Research Institute : A Proposal for Earthquake Resistant Design Method, Technical Memorandum of PWRI, No.1185, 1977 (in Japanese).

2) Iwan, W.D. ed. : Strong-Motion Earthquake Instrument Arrays, Proc. of International Workshop on StrongMotion Earthquake Instrument Arrays, May, 1978.

3) Bolt, B.A., Loh, C.H., Penzien, J. and Tsai, Y.B. : Preliminary Report on the SMART-1 Array in Taiwan. Earthquake Engineering Research Center Report, No. UCB/EERC-82/13, University of California, Berkeley, 1982.

4) Iwasaki, T., Sasaki, Y., Tamura, K., Aizawa, K. and Takahashi, K.: Dense Instrument Array System by PWRI for Observing Strong Earthquake Motion, 18th Joint Meeting, U. S.-Japan Panel on Wind and Seismic Effects, UJNR, May, 1986.

5) Tamura, K., Winterstein, S. R. and Shah, H.C. : Random Field Models of Spatially Varying Ground Motions, The John A. Blume Earthquake Engineering Center Report, No.92, Stanford University, October, 1990.

6) Hoshiya, M., Ishii, K. and Kurita, H. : Simulation of Spatially and Temporally Variative Earthquake Ground Motions, Proc. of Japan Society of Civil Engineers, No.386/I-8, 1987 (in Japanese). 
7) Kawakami, H. and Sato, Y. : Effect of Deformation of Seismic Waves on Estimated Value of Ground Relative Displacement or Strain, Proc. of Japan Society of Civil Engineers, No.337, 1983 (in Japanese).

8) Loh, C.H. : Analysis of the Spatial Variation of Seismic Waves and Ground Movements from SMART-1 Array Data, Earthquake Engineering and Structural Dynamics, Vol.13, No.5, 1985.

9) Harichandran, R.S. and Vanmarcke, E.H. : Stochastic Variation of Earthquake Ground Motion in Space and Time, Journal of Engineering Mechanics, ASCE, Vol.112, No.2, 1986.

10) Harada, T. : Probabilistic Modeling of Spatial Variation of Strong Earthquake Ground Displacements, Proc. of 8th World Conference on Earthquake Engineering, July, 1984.

11) Loh, C.H. and Yeh, Y.T. : Spatial Variation and Stochastic Modeling of Seismic Differential Ground Movement, Earthquake Engineering and Structural Dynamics, Vol.16, No.4, 1988.

12) Harada, T. and Shinozuka, M. : Stochastic Analysis of Seismic Ground Motions in Space and Time, Proc. of 9th
World Conference on Earthquake Engineering, August, 1988.

13) Deodatis, G. and Shinozuka, M. : Simulation of Seismic Ground Motion Using Stochastic Waves, Journal of Engineering Mechanics, ASCE, Vol.115, No.12, 1989.

14) Vanmarcke, E.H. : Random Fields, MIT Press, 1983.

15) Vanmarcke, E.H. and Lai, S.-S.P. : Strong-Motion Duration and RMS Amplitude of Earthquake Records, Bulletin of Seismological Society of America, Vol.70, No.4, 1980.

16) Goto, H., Kameda, H., Sugito, M. and Imanishi, N. : Correction of SMAC-B2 Accelerograph Records by Digital Filter, Proc. of Japan Society of Civil Engineers, No.277, 1978 (in Japanese).

17) Tamura, K., Kawashima, K., Aizawa, K. and Takahasi, K. : Accuracy of Digital Strong-Motion Accelerograph with Independent Triggering and Recording System for Analysis of Finite Ground Strains during Earthquake, Proc. of Japan Society of Civil Engineers, No.392/I-9, 1988 (in Japanese).

(Received November 8, 1990)

\title{
空間変動を有する地震動モデルおよびその相対地震動評価 への応用
}

\author{
田村敬一・Steven R. WINTERSTEIN, ・ Haresh C. SHAH
}

本研究は, 地中構造物の耐震設計上重要な地震時の地盤ひずみ（相対変位）を評価す ることを目的として, 2 種類の簡便な地震動の時間一空間確率過程モデルを提案し, そ れを基に 2 地点間の最大相対変位の評価を試みたものである. 提案モデルは，一般に仮 定される地震動の時間一空間クロススペクトル密度関数のモデルより導出されたもので あり，その有効性については高密度強震観測記録と比較することに検証した. 